\title{
CrystEngComm
}

Check for updates

Cite this: CrystEngComm, 2020, 22, 986

Received 23rd August 2019,

Accepted 6th December 2019

DOI: $10.1039 /$ c9ce01333d

rsc.li/crystengcomm

\section{Heteromolecular compounds in binary systems of amino acids with opposite and same chiralities $\uparrow$}

\author{
Anton I. Isakov, ${ }^{a}$ Heike Lorenz, iD *b \\ Andrey A. Zolotarev Jr (iD a and Elena N. Kotelnikova (iD ${ }^{a}$
}

\begin{abstract}
A classification of discrete compounds in binary chiral systems of single and different substances (homoand heteromolecular compounds) is presented. It considers both chemical and crystallographic characteristics of such compounds. Using amino acids as chiral model systems, features of crystal structures of equimolar and non-equimolar heteromolecular compounds are reviewed. In this connection, the concept of homo- and heteromolecular dimers in compounds formed by amino acids is introduced and analyzed. As a result, a correlation between the molecular dimer type and the side chain structure (linear or branched) and the conformation (extended or folded) of the relevant compounds' molecules is derived. Two non-equimolar discrete heterocompounds discovered in the chiral systems L-valine-Lisoleucine and L-valine-L-leucine are discussed using the concepts proposed. The previously studied first system features a 2:1 (Val: lle) compound. A newly investigated second system is found to form a 3:1 (Val: Leu) compound, and its crystal structure is described and evaluated.
\end{abstract}

\section{Introduction}

Many organic substances are chiral molecules, which can exist as levo and dextrorotatory optical antipodes. These molecular entities being mirror images of each other and non-superposable are called enantiomers. ${ }^{1}$ In their molecular structures, enantiomers possess a chiral element, which in most cases is a chiral center and less frequently, a chiral plane or a chiral axis. Usually, the chiral center is a so-called asymmetric carbon atom, i.e. a carbon atom interlinked by "tetrahedral" bonds to four different substituents (ligands). Chiral molecules may have various numbers of chiral centers (n), with $n$ defining the number of possible configurations of the molecule $\left(2^{n}\right)$. In a symmetric environment, all the physical and chemical properties of enantiomers are identical, except for the direction of plane-polarized light rotation.

Size and shape of molecules and geometry of intermolecular hydrogen bonds are general factors influencing the molecular packing in crystal structures of organic substances. ${ }^{2,3}$ In the case of chiral substances, the

\footnotetext{
${ }^{a}$ Department of Crystallography, Saint Petersburg State University,

Universitetskaya emb. 7/9, 199034 Saint Petersburg, Russia

${ }^{b}$ Max Planck Institute for Dynamics of Complex Technical Systems, Sandtorstrasse

1, 39106 Magdeburg, Germany. E-mail: lorenz@mpi-magdeburg-mpg.de;

Tel: +49 3916110293

$\dagger$ CCDC 1903257. For crystallographic data in CIF or other electronic format see DOI: $10.1039 /$ c9ce01333d
}

molecule configuration becomes the main additional factor for molecular packing.

Enantiomers are widely used in pharmaceuticals, food industries and electronics. For example, in 2004, nine out of the ten most sold drugs contained chiral active ingredients. ${ }^{4}$ Furthermore, in the same year, among the 16 newly approved synthetic drugs, 13 were chiral with all of them being single enantiomers. ${ }^{5}$ However, products of non-stereoselective industrial synthesis are mixtures of both enantiomers. Therefore, the problem of applicability of chiral substances (for example, for API's production) is closely connected to the problem of resolution of enantiomeric mixtures. The most profitable resolution methods are crystallization methods that require the understanding of phase equilibria in a system and plotting its phase diagram. ${ }^{6}$

The largest part of published information on chiral systems refers to enantiomers of a single substance, while reports on enantiomeric systems of different substances are rather rare. Amino acids are suitable model compounds to investigate binary chiral systems of the latter type. The great diversity of amino acids and relatively simple structures of their molecules made them already model compounds, for example, for the determination of hydrogen bond lengths in proteins and other biopolymers. ${ }^{7,8}$

The vast variety of proteins is a result of the combination of twenty proteinogenic $\alpha$-amino acids, with nineteen being chiral compounds. Among them, seventeen molecules contain only one asymmetric carbon atom and, consequently, exist as two enantiomers. Molecules of the residual amino 
acids, threonine and isoleucine, contain two asymmetric carbon atoms and thus, exist as four stereoisomers forming two enantiomer and four diastereomer pairs, respectively. Eight proteinogenic $\alpha$-amino acids are essential amino acids, which cannot be produced by the human body and, therefore, must be consumed. The subjects of our study, the aliphatic amino acids valine $\left(\mathrm{C}_{5} \mathrm{H}_{11} \mathrm{NO}_{2}\right)$, leucine $\left(\mathrm{C}_{6} \mathrm{H}_{13} \mathrm{NO}_{2}\right)$, and isoleucine $\left(\mathrm{C}_{6} \mathrm{H}_{13} \mathrm{NO}_{2}\right)$, belong to this group.

In this present work, we (1) introduce a classification of discrete compounds formed in chiral systems (section 2), (2) discuss the chiral molecular packing in crystal structures of amino acids and their equimolar heteromolecular compounds (sections 3 and 4), and (3) present detailed studies of mainly two levorotatory amino acid systems, L-valine-L-leucine and L-valineL-isoleucine, as examples of binary chiral systems forming non-equimolar heteromolecular compounds (section 5).

\section{Classification of discrete compounds in binary systems of chiral molecules}

A first classification attempt for such compounds was proposed by the present authors earlier. ${ }^{9}$ We considered the classification necessary, since in the literature, there is plenty of information available on various types of chiral compounds, but, at the same time, the compounds are described using "spontaneously arisen" terms which are not self-sufficient, i.e. they do not reflect the proper place of a particular compound in the general hierarchy of chiral substances.

The revised classification is shown as a flow diagram in Fig. 1. We implemented significant changes, namely, the proposed concepts for homo- and heteromolecular dimers (see sections 4.1 and 4.2), and considered diastereomers to be different substances, differing on molecular structures and physical characteristics. However, the key change is an improved order of basic chemical and crystallographic classifying features that define the hierarchy of chiral compounds.

The chemical composition of a particular compound became the first classifying feature, and the molecular ratio of the components constituting a compound as the second classifying feature. Consequently, in Fig. 1, compounds formed in binary chiral systems were first divided into two main types: homomolecular and heteromolecular discrete compounds. Afterwards, they were split into equimolar and non-equimolar compounds, respectively.

In the case of homomolecular compounds (homocompounds), the third classifying feature is based on the molecular packings' character in the crystal structure. Accordingly, equimolar homocompounds are divided into compounds with symmetry related molecular components (centrosymmetric and non-centrosymmetric ones) and compounds with symmetrically independent molecular components. Exemplary centrosymmetric and non-

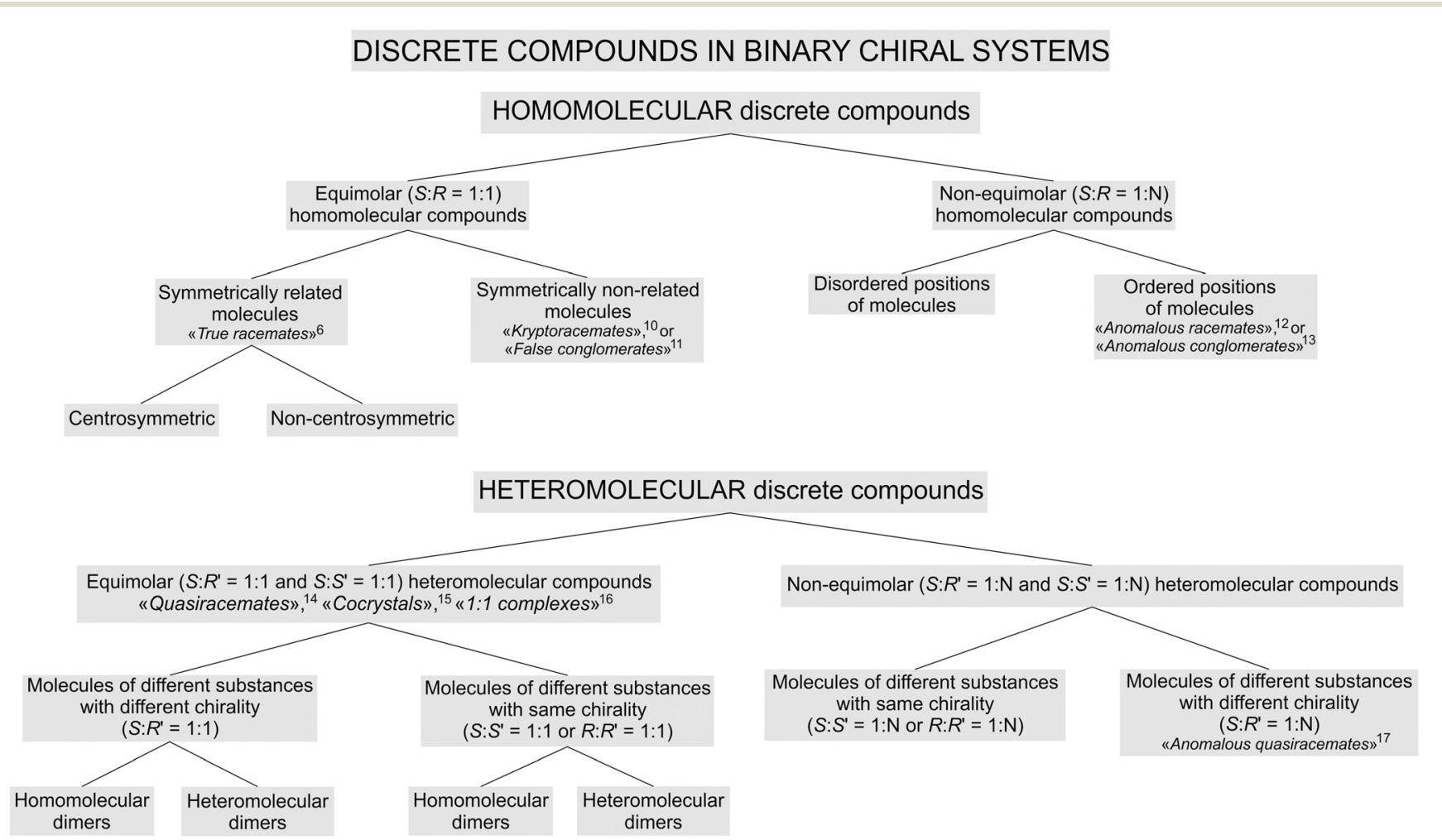

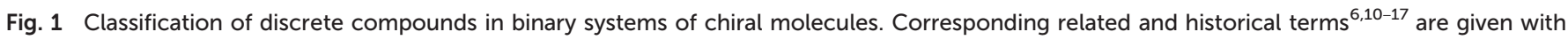
references. 
a

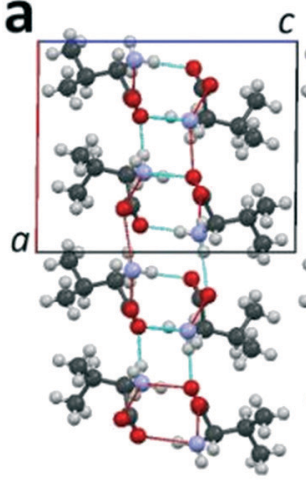

layer $c$

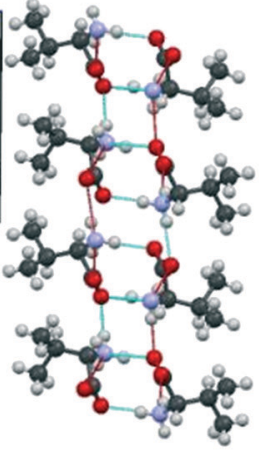

b

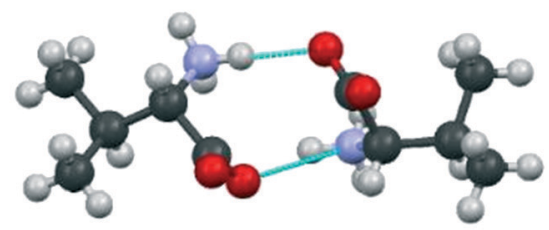

Fig. 2 Projection of the L-valine crystal structure on the ac plane of the monoclinic cell (a) and its dimer molecule (b). Hereinafter, dotted lines are the hydrogen bonds. Images are constructed in the program Mercury ${ }^{40}$ using the structural data CSD LVALINO1. ${ }^{33}$

centrosymmetric equimolar homocompounds are two polymorphs of malic acids' true racemate, RSI and RSII, respectively. ${ }^{9}$ An exemplary homocompound containing symmetrically independent molecules is DL-allylglycine. ${ }^{18}$

Non-equimolar homocompounds, in turn, can be divided into compounds having ordered and disordered molecular positions. An exemplary compound with ordered molecular positions is the non-equimolar discrete compound $S_{3} R$ of malic acid. ${ }^{9,19}$ To the present authors' knowledge, there is no available information in the literature about any nonequimolar homocompounds with disordered molecular positions.

In the case of heteromolecular compounds (heterocompounds), the third classifying feature is the chirality of the molecular components. Accordingly, equimolar heterocompounds are divided into compounds composed of molecular components with different chiralities and ones with the same chirality. The crystal structure of heterocompounds of either type can consist of homomolecular or heteromolecular dimers.

In other words, systems with components having different chiralities can produce compounds containing homomolecular dimers (e.g., L-valine-D-norvaline, see section 4.1) and compounds containing heteromolecular dimers (e.g., D-valine-L-leucine, see section 4.2). Heterocompounds with homomolecular dimers are found not only among amino acids but also among other chiral organic compounds. ${ }^{20-25}$ As well as systems of components having the same chirality can form compounds containing heteromolecular dimers (e.g., L-malic acid-L-tartaric acid $^{26}$ ) and, possibly, those consisting of homomolecular dimers (no examples have been found yet in the published literature).

Similarly, non-equimolar heterocompounds are divided into compounds composed of molecular components with the same or different chiralities. The latter case is found in heterocompounds formed in the (+)-2,4-dimethylglutaric acid-(-)-dilactic acid and (-)-2,4-dimethylglutaric acid-(+)-2methylglutaric acid systems. ${ }^{14}$ In contrast, the molecular components of non-equimolar heterocompounds found by the present authors in the systems of $\mathrm{L}$-valine- $\mathrm{L}$-isoleucine $\mathrm{e}^{9,27}$ and L-valine-L-leucine (see section 5) have the same chirality.

\section{Crystal structure of amino acids}

The publications ${ }^{7-9,16,27-35}$ that appeared in the last decades made a considerable contribution to the concept of molecular structures of amino acids.

For the description of the amino acids' crystal structure, the terms "dimer" and "molecular layer",27,36-38 will be used. The enantiomer $\mathrm{L}$-valine is applied here as a representative example of a typical aliphatic amino acid. Fig. 2a shows the projection of the L-valine crystal structure onto the $a c$ plane. In the crystal structure, it is possible to distinguish dimers consisting of two levorotatory valine molecules interlinked with hydrogen bonds (Fig. 2b). Pairing of molecules with formation of a dimer is typical for hydrophobic amino acids. ${ }^{7}$ Each dimer is bonded to neighbor dimers in the $a b$ plane via hydrogen bonds. Thus, the thickness of the formed molecular layer in the direction of the $c$ axis is equal to one dimer molecule (two valine molecules) (Fig. 2a). The layers are interlinked via the van der Waals bonds.

\section{Crystal structure of equimolar heterocompounds of amino acids}

In the literature, there are no data found on equimolar heterocompounds of amino acids having the same chirality. Therefore, this present article concentrates on compounds with molecular components that possess different chiralities, i.e. different signs of optical activity $S: R^{\prime}=1: 1$ (see Fig. 1). A considerable contribution to the investigation of such heterocompounds was made by C. H. Görbitz, B. Dalhus and co-workers. ${ }^{7,16,28-32,41}$ They systematically studied equimolar compounds composed of molecules of different amino acids using SCXRD techniques. These compounds have been

$\ddagger$ C. H. Görbitz ${ }^{7,39}$ uses the term "bilayer" to define such layers. 
mentioned under various names including " $1: 1$ complexes", ${ }^{16,29,31,32 \quad \text { "diastereomeric complexes", } 30}$ "pseudoracemic complexes", ${ }^{41}$ and "quasiracemates", 7,28 To describe the interactions of different molecules in crystal structures of these compounds, C. H. Görbitz ${ }^{7}$ used designations LD-LD and L1-D1 in accordance with the geometry of the hydrogen bonds formed. In the following, the terms homo- and heteromolecular dimers are used to describe the crystal structures of amino acid heterocompounds.

\subsection{Equimolar heterocompounds of amino acids with homomolecular dimers}

Heterocompounds of this type will be examined on the example of an equimolar discrete compound formed in the amino acids' system L-valine-D-norvaline. ${ }^{31}$ Fig. $3 \mathrm{a}$ and $\mathrm{b}$ show the homomolecular dimer molecules of $\mathrm{L}$-valine and $\mathrm{D}^{-}$ norvaline, respectively. Fig. $3 \mathrm{c}$ presents the projection onto the ac plane of the crystal structure (S. G. C2) of the equimolar discrete compound of L-valine and D-norvaline molecules. In its crystal structure, it is possible to distinguish molecular layers having a thickness of one dimer molecule. The homomolecular dimers of valine and norvaline are alternating within each layer. The molecular layers are practically perpendicular to the $c$ axis of the monoclinic cell. Neighbor layers are shifted along the $a$ axis with respect to each other and, therefore, the translation along the $c$ axis includes two molecular layers. Consequently, the monoclinic cell of the heterocompound doubled in size in comparison to that of L-valine (see Fig. 2).

\subsection{Equimolar heterocompounds of amino acids with heteromolecular dimers}

Heterocompounds of this type will be examined on the example of an equimolar discrete compound formed in the amino acids' system D-valine-L-leucine. ${ }^{31}$ Fig. 4a shows a heteromolecular dimer molecule composed of D-valine and L-leucine molecules. In Fig. $4 \mathrm{~b}$, the projection onto the $b c$ plane of the crystal structure (S. G. $P 2_{1}$ ) of the equimolar compound of D-valine and L-leucine molecules is presented. In this crystal structure, it is also possible to distinguish the molecular layers having a thickness of one dimer molecule. It is very important to note that in this case, all the dimeric molecules are identical. It can be seen that the neighbor layers are rotated by $180^{\circ}$ in the $a b$ plane with respect to each other (Fig. 4b). Consequently, in this case, the translation along the $c$ axis also includes two molecular layers.

\subsection{Discussion}

The concept of homo- and heteromolecular dimers is considered in the classification of discrete compounds in binary chiral systems (Fig. 1). This concept is also reflected in Tables 1 and 2, created using the results obtained by C. $\mathrm{H}$. Görbitz, B. Dalhus and co-workers. ${ }^{7,16,28-32}$ It should be noted that only the equimolar heterocompounds of amino acids having components with different chiralities were studied. Among them, we consider here only the compounds whose crystal structures have been deciphered.

In Table 1, the $\mathrm{L}$ and $\mathrm{D}$ components of a heterocompound are arranged in separate columns. The equimolar heterocompounds of aliphatic $\alpha$-amino acids with homo- and heteromolecular dimers are listed in parts 1 and 2 of Table 1, respectively. Each part comprises two categories, distinguished in accordance with the structure of radical $\mathrm{R}$ or the structure of the side chain of the corresponding $\alpha$-amino acid (see Fig. 5 and 6). The side chain can be branched or linear. For example, molecules of valine $\left(\mathrm{C}_{5} \mathrm{H}_{11} \mathrm{NO}_{2}\right)$, leucine $\left(\mathrm{C}_{6} \mathrm{H}_{13} \mathrm{NO}_{2}\right)$, and isoleucine $\left(\mathrm{C}_{6} \mathrm{H}_{13} \mathrm{NO}_{2}\right)$ (Fig. 6a) have a branched side chain, while molecules of norvaline $\left(\mathrm{C}_{5} \mathrm{H}_{11} \mathrm{NO}_{2}\right)$, norleucine $\left(\mathrm{C}_{6} \mathrm{H}_{13} \mathrm{NO}_{2}\right)$, and methionine $\left(\mathrm{C}_{5} \mathrm{H}_{11} \mathrm{NO}_{2} \mathrm{~S}\right)$ (Fig. 6b) possess a linear one.

In the heterocompounds with homomolecular dimers (Table 1, part 1), category 1a includes two compounds, wherein both molecular components are linear. Category $1 \mathrm{~b}$ comprises ten compounds with the L component being branched and the D component linear. In the heterocompounds with heteromolecular dimers (Table 1, part 2 ), category $2 \mathrm{a}$ includes five compounds, wherein both constituents are branched. Category $2 \mathrm{~b}$ comprises four

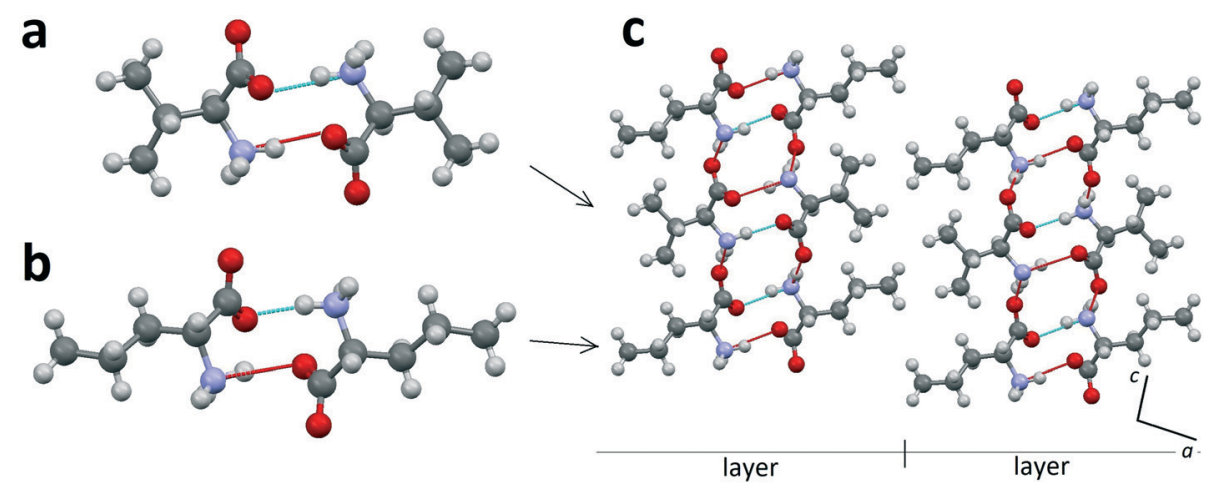

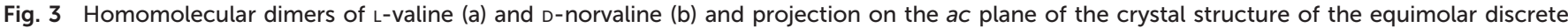
compound in the L-valine-D-norvaline system (c). Images are constructed in the program Mercury ${ }^{40}$ using the structural data CSD BERQEU. ${ }^{31}$ 


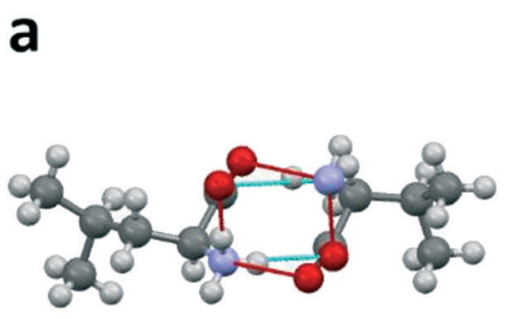

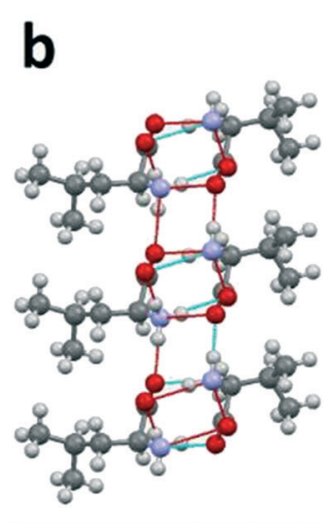

layer

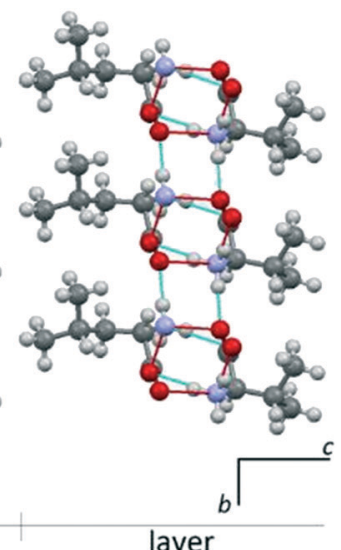

layer

Fig. 4 L-Leucine-D-valine dimer molecule (a) and projection on the bc plane of the crystal structure of the equimolar heterocompound in the $D$ valine-L-leucine system (b). Images are constructed in the program Mercury ${ }^{40}$ using the structural data CSD BERPET. ${ }^{31}$

Table 1 Equimolar heterocompounds formed in the binary systems of aliphatic L- and D-amino acids

1. Equimolar heterocompounds of amino acids with homomolecular dimers

1a. Same type of side chains in molecular components

\begin{tabular}{llll}
\hline No. & $\begin{array}{l}\text { Linear molecule } \\
\text { (component 1) }\end{array}$ & $\begin{array}{l}\text { Linear molecule } \\
\text { (component 2) }\end{array}$ & Ref. \\
\hline 1 & L-Norvaline & D-Norleucine & 16 \\
2 & L-Methionine & D-Norleucine & 16 \\
\hline
\end{tabular}

1b. Different types of side chains in molecular components

\begin{tabular}{lll}
$\begin{array}{l}\text { Branched molecule } \\
\text { (component 1) }\end{array}$ & $\begin{array}{l}\text { Linear molecule } \\
\text { (component 2) }\end{array}$ & Ref. \\
\hline L-Valine & D- $\alpha$-Aminobutyric acid & 31 \\
L-Valine & D-Norvaline & 31 \\
L-Valine & D-Methionine & 31 \\
L-Valine & D-Norleucine & 16 \\
L-Isoleucine & D-Alanine & 29 \\
L-Isoleucine & D-Norleucine & 29 \\
L-Isoleucine & D-Norvaline & 29 \\
L-Isoleucine & D-Methionine & 29 \\
L-Isoleucine & D- $\alpha$-Aminobutyric acid & 29 \\
L-allo-Isoleucine & D-Norleucine & 16 \\
\hline
\end{tabular}

2. Equimolar heterocompounds of amino acids with heteromolecular dimers

\begin{tabular}{llll}
\hline \multicolumn{2}{l}{ 2a. Same type of side chains in molecular components } \\
\hline No. & $\begin{array}{l}\text { Branched molecule } \\
\text { (component 1) }\end{array}$ & $\begin{array}{l}\text { Branched molecule } \\
\text { (component 2) }\end{array}$ & Ref. \\
\hline 1 & L-Leucine & D-Valine & 31 \\
2 & L-Leucine & D-allo-Isoleucine & 7 \\
3 & L-Isoleucine & D-allo-Isoleucine & 30 \\
4 & L-Isoleucine & D-Valine & 29 \\
5 & L-Isoleucine & D-Leucine & 29 \\
\hline
\end{tabular}

2b. Different types of side chains in molecular components

\begin{tabular}{llll}
\hline No. & $\begin{array}{l}\text { Branched molecule } \\
\text { (component 1) }\end{array}$ & $\begin{array}{l}\text { Linear molecule } \\
\text { (component 2) }\end{array}$ & Ref. \\
\hline 1 & L-Leucine & D-Norleucine & 16 \\
2 & L-Leucine & D- $\alpha$-Aminobutyric acid & 31 \\
3 & L-Leucine & D-Norvaline & 31 \\
4 & L-Leucine & D-Methionine & 31
\end{tabular}

compounds wherein the L component is branched, while the $\mathrm{D}$ component is linear.

This method of examining the equimolar heterocompounds of amino acids reveals a connection between the type of molecular dimers (homo- or heteromolecular) and the side chain structure of the molecular components (branched or linear). As seen in Table 1, all the heterocompounds composed of molecular components with linear side chains belong to group 1, i.e. have homomolecular dimers. In turn, all the heterocompounds consisting of components with branched side chains belong to group 2, i.e. feature heteromolecular dimers.

More complex is the case when one of the heterocompound components is characterized by a branched molecule and the other by a linear molecule. Compounds of such a type are present in both parts in Table 1 . Affinity of a particular compound toward part 1 or 2 likely depends on the nature of the branched molecular component. It turned out that if the branched component is valine, isoleucine, or allo-isoleucine (part 1b, Table 1), then the heterocompound has homomolecular dimers. In turn, if the branched component is leucine (part $2 \mathrm{~b}$, Table 1), then the resulting heterocompound has heteromolecular dimers.

A probable explanation is based on the following. There are two conformations of molecules in the crystal structures of valine, isoleucine, and allo-isoleucine (Table 2). Relative to each other, one of the conformations can be considered as "extended" (Fig. 7a) and the other one as "folded" (Fig. 7b). The differences between the extended and folded conformations are clearly seen from the comparison of the corresponding torsion angles in Fig. 7.

In the case of the equimolar homocompounds (true racemates $\mathrm{LD}$, Fig. 1), molecules of valine, isoleucine, and allo-isoleucine adopt the folded conformation. In contrast, in the case of the equimolar heterocompounds ("quasiracemates" LD', Fig. 1), they have the extended conformation. This is confirmed by the examples of four 
<smiles>[R]C(N)C(=O)O</smiles>

Fig. 5 General formula of $\alpha$-amino acids ( $\mathrm{R}$ - radical or side chain).

heterocompounds containing valine, five heterocompounds containing isoleucine, and one heterocompound comprising allo-isoleucine (see Tables 1 and 2). Another situation occurs in the case of leucine. All the molecules in the crystal structure of L-leucine are identical and, consequently, there is no need to attribute a conformation. It was found that all the heterocompounds containing leucine and linear molecules of other amino acids form heteromolecular dimers (see $2 \mathrm{~b}$ in Table 1).

Table 3 summarizes the equimolar heterocompounds with the $\mathrm{L}$ component being the aromatic $\alpha$-amino acid phenylalanine $\left(\mathrm{C}_{9} \mathrm{H}_{11} \mathrm{NO}_{2}\right)$ and the $\mathrm{D}$ component as an aliphatic amino acid. Similar to Table 1, Table 3 consists of two parts comprising heterocompounds with homo- and heteromolecular dimers, respectively. The phenylalanine molecule (component 1 ) is considered as branched, since it contains a phenyl group. The molecules of the aliphatic amino acids (component 2) are both branched and linear molecules.

Heterocompounds with homomolecular dimers (Table 3, part 1) are represented exclusively by compounds whose both the components have branched molecules and one of the components is aromatic, while the other one is aliphatic. It should be noted that when both branched components are aliphatic molecules (see $2 \mathrm{a}$ in Table 1), the resulting heterocompound, in contrast, is composed of heteromolecular dimers.

Heterocompounds with heteromolecular dimers (Table 3, part 2) are represented solely by compounds whose one of the components has a branched molecule (aromatic component), while the other one has a linear molecule (aliphatic component). Thus, as in the case of heterocompounds composed of two aliphatic amino acids, the configuration of the molecular side chain greatly affects the structure of the equimolar heterocompounds containing an aromatic phenylalanine molecule.

Table 2 Conformations of the branched molecules of valine, isoleucine, and allo-isoleucine in different compounds

\begin{tabular}{llll}
\hline & \multicolumn{2}{l}{ Conformation of molecule } & \\
\cline { 2 - 4 } Amino acid & Enantiomer L & $\begin{array}{l}\text { True } \\
\text { racemate LD }\end{array}$ & $\begin{array}{l}\text { Heterocompound } \\
\text { LD }^{\prime}\end{array}$ \\
\hline Valine & $\begin{array}{l}\text { Extended } \\
\text { and folded }\end{array}$ & Folded & Extended \\
Isoleucine & $\begin{array}{l}\text { Extended } \\
\text { and folded } \\
\text { allo-Isoleucine }\end{array}$ & Folded & Extended \\
Extended & No data & Extended
\end{tabular}
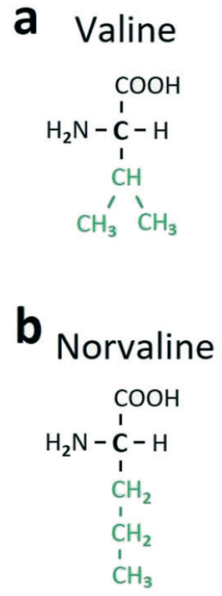

Leucine<smiles>CC(C)CC(N)C(=O)O</smiles>

Norleucine

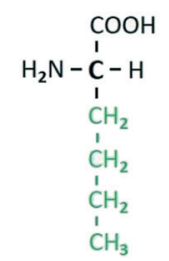

Isoleucine<smiles>CCC(C)C(N)C(=O)O</smiles>

Methionine

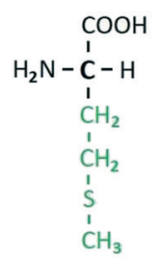

Fig. 6 Structural formulae of certain aliphatic $\alpha$-amino acids with branched (a) and linear (b) side chains (colored in green).

\section{Crystal structure of non-equimolar heterocompounds of amino acids}

In the literature, we did not find examples of non-equimolar heterocompounds of amino acids with different chiralities where their crystal structure is known (see also Fig. 1). Therefore, in the following we focus on compounds composed of amino acids of the same chirality. One has already been reported by the authors, while the other one is new and its crystal structure will be presented and discussed below.

\subsection{Non-equimolar heterocompounds with molecules of the same chirality}

Table 4 comprises the two amino acid systems, namely Lvaline-L-isoleucine and L-valine-L-leucine, together with the associated non-equimolar compounds found. In the first one, a molecular component ratio of Val: Ile $=2: 1 \S$ was determined and the compound was designated as $\mathrm{V}_{2} \mathrm{I}^{27}$ The related results, including the crystal structure of compound $\mathrm{V}_{2} \mathrm{I}$, limits of solid solutions in the system, and thermal deformations of the system components and compound $\mathrm{V}_{2} \mathrm{I}$, are discussed in detail in the previous studies. $^{9,27,37}$ The newly discovered compound in the $\mathrm{L}^{-}$ valine-L-leucine system has a molecular ratio of Val: Leu = $3: 1$ and is denoted $\mathrm{V}_{3} \mathrm{~L}$.

\subsection{Crystal structure of the non-equimolar heterocompound $\mathbf{V}_{3} \mathbf{L}$}

Samples of mixtures containing various contents of valine and leucine were prepared by isothermal crystallization. The reactants used were $\mathrm{L}(+)$-valine and $\mathrm{L}(+)$-leucine of $99 \%$ purity,

$\S$ Hereinafter, international abbreviations of the amino acid names are used: Val for valine, Ile for isoleucine, and Leu for leucine. 

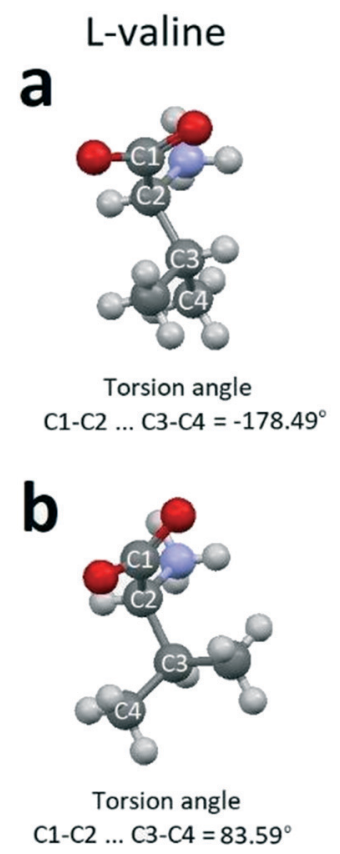

L-isoleucine

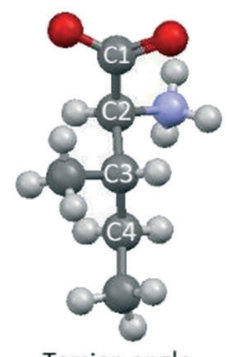

Torsion angle

$\mathrm{C} 1-\mathrm{C} 2 \ldots \mathrm{C} 3-\mathrm{C} 4=-177.43^{\circ}$

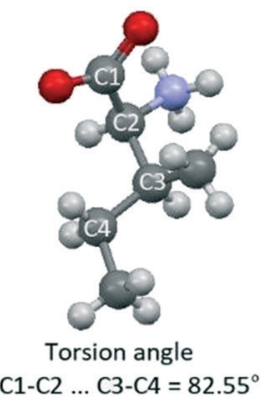

D-allo-isoleucine

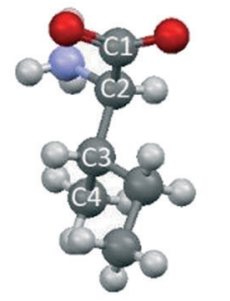

Torsion angle

C1 $-\mathrm{C} 2$... C3-C4 $=176.63^{\circ}$

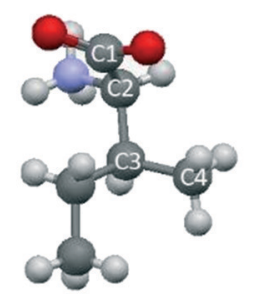

Torsion angle

$\mathrm{C} 1-\mathrm{C} 2 \ldots \mathrm{C} 3-\mathrm{C} 4=-84.83^{\circ}$

Fig. 7 Extended (a) and folded (b) conformations of valine, isoleucine and allo-isoleucine molecules. Images are constructed in the program Mercury $^{40}$ using the structural data CSD LVALIN01, LISLEU02 and DAILEU01, respectively.

purchased from Alfa Aesar, Massachusetts, USA. Pre-weighted mixtures of the reactants were put into a weighing bottle and dissolved in distilled water at $25{ }^{\circ} \mathrm{C}$ under continuous stirring with a glass rod. Water was added until complete dissolution of the substance. Then, the bottle was loosely covered with a cap and kept undisturbed for a period of at least three weeks at $25{ }^{\circ} \mathrm{C}$ until the solvent was completely evaporated. Precipitates were then analyzed by means of powder X-ray diffraction (PXRD) techniques. Fifteen samples of the prepared valine/leucine mixtures having a varying composition were studied using a Rigaku MiniFlex II diffractometer with the following settings: $\mathrm{CuK} \alpha$ radiation, a

Table 3 Equimolar heterocompounds in the binary systems of Lphenylalanine and various aliphatic $D$-amino acids

\begin{tabular}{llll}
\hline \multicolumn{4}{l}{ 1. Equimolar heterocompounds with homomolecular dimers } \\
\hline \multicolumn{4}{l}{ Same type of side chains in molecular components } \\
No. & $\begin{array}{l}\text { Branched molecule } \\
\text { (component 1) }\end{array}$ & $\begin{array}{l}\text { Branched molecule } \\
\text { (component 2) }\end{array}$ & Ref. \\
\hline 1 & L-Phenylalanine & D-Leucine & 32 \\
2 & L-Phenylalanine & D-Isoleucine & 32 \\
3 & L-Phenylalanine & D-allo-Isoleucine & 32 \\
\hline
\end{tabular}

2. Equimolar heterocompounds with heteromolecular dimers Different types of side chains in molecular components

\begin{tabular}{llll}
\hline No. & $\begin{array}{l}\text { Branched molecule } \\
\text { (component 1) }\end{array}$ & $\begin{array}{l}\text { Linear molecule } \\
\text { (component 2) }\end{array}$ & Ref. \\
\hline 1 & L-Phenylalanine & D-Norvaline & 32 \\
2 & L-Phenylalanine & D- $\alpha$-Aminobutyric acid & 32 \\
3 & L-Phenylalanine & D-Methionine & 32
\end{tabular}

Table 4 Non-equimolar heterocompounds in the binary systems of amino acids with the same chirality

\begin{tabular}{lll}
\hline System & $\begin{array}{l}\text { Non-equimolar } \\
\text { heterocompound }\end{array}$ & $\begin{array}{l}\text { Component } \\
\text { ratio }\end{array}$ \\
\hline L-Valine-L-isoleucine $^{9,27,37}$ & $\mathrm{~V}_{2} \mathrm{I}$ & $2: 1$ \\
L-Valine-L-leucine $^{42}$ & $\mathrm{~V}_{3} \mathrm{~L}$ & $3: 1$
\end{tabular}

scan speed of $2^{\circ} \mathrm{min}^{-1}$, a step of $0.02^{\circ}$, and $2 \theta$ range $=3-40^{\circ}$. The obtained PXRD data suggested the formation of the new compound $\mathrm{V}_{3} \mathrm{~L}$ having a molar ratio of Val: Leu $=3: 1$. As seen in Fig. 8, the diffraction pattern of this compound differs from those of the system components Val and Leu and is not their combination. Accordingly, two two-phase regions were observed in-between monophasic areas corresponding to compounds $\mathrm{V}_{3} \mathrm{~L}$, Val and Leu. The PXRD data showed that the major volume of the $75 \mathrm{~mol} \% \mathrm{Val} / 25$ mol\% Leu sample belongs to phase $\mathrm{V}_{3} \mathrm{~L}$, and the diffraction peaks of other phases are practically absent. The most wellshaped crystal found in the sample was taken for structural analysis.

Structural analysis of a $\mathrm{V}_{3} \mathrm{~L}$ single crystal was performed using a diffractometer Agilent Technologies SuperNova with $\mathrm{CuK} \alpha$ radiation and at a temperature of $100 \mathrm{~K}$. The structure has been solved by direct methods and refined by means of the SHELX program incorporated in the OLEX2 program package. The carbon- and nitrogen-bound $\mathrm{H}$ atoms were placed in calculated positions and included in the refinement in the 'riding' model approximation. The 


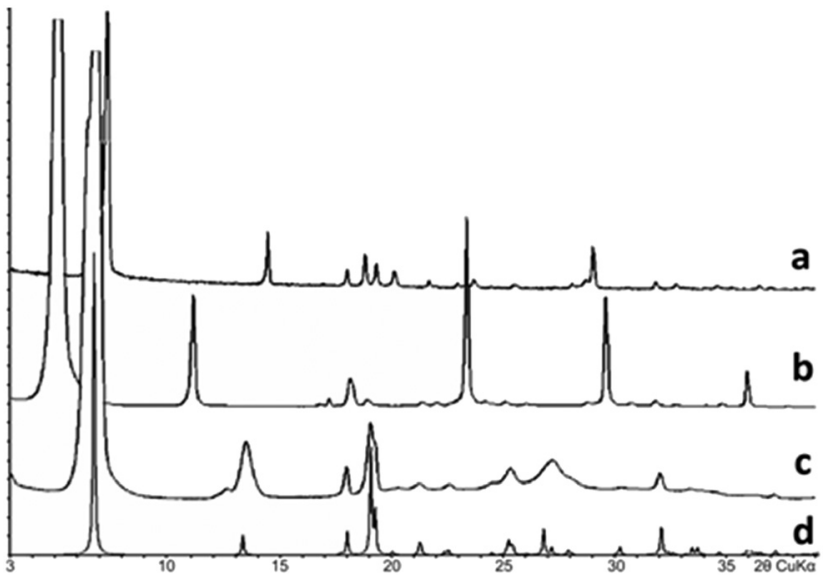

Fig. 8 Diffractograms of L-Val (a) and L-Leu (b). Experimental (c) and calculated (d) diffraction patterns of the compound $V_{3} L$ obtained by means of powder and single crystal diffraction, respectively.

experimental conditions applied and crystal structure parameters of the non-equimolar heterocompound $\mathrm{V}_{3} \mathrm{~L}$ are summarized in Table 5. Fig. 9 shows the projection of the $\mathrm{V}_{3} \mathrm{I}$ compounds' crystal structure onto the ac plane of the monoclinic cell (Fig. 9a) and the $\mathrm{V}_{3} \mathrm{~L}$ dimer molecule (Fig. 9b).

Heterocompound $\mathrm{V}_{3} \mathrm{~L}$ contains the molecules of valine and leucine in a ratio of $3: 1$. Two out of four molecular positions in the unit cell $(Z=4)$ are independent. One of the independent positions is occupied by a valine molecule ( 1 Val) (Fig. 9b, left part). The other independent position is disordered, i.e. it is characterized by mixed occupation. It can be occupied with equal probability by either a valine or leucine molecule $(1 / 2 \mathrm{Val}+1 / 2 \mathrm{Leu})$ (Fig. $9 \mathrm{~b}$, right part). Therefore, the total number of valine molecules in the compounds' unit cell is $(1+1 / 2) \times 2=3$, while the total number of leucine molecules is $1 / 2 \times 2=1$. Consequently,
Table 5 Crystal structure data and structure refinement for the discrete heterocompound $\mathrm{V}_{3} \mathrm{~L}$

\begin{tabular}{|c|c|}
\hline Empirical formula & $\mathrm{C}_{21} \mathrm{H}_{46} \mathrm{~N}_{4} \mathrm{O}_{8}$ \\
\hline Formula weight & 482.62 \\
\hline Temperature/K & 100 \\
\hline Crystal system & Monoclinic \\
\hline Space group & $P 2_{1}$ \\
\hline$a / \AA$ & $9.6267(7)$ \\
\hline$b / \AA$ & $5.2704(2)$ \\
\hline$c / \AA$ & $13.8290(17)$ \\
\hline$\alpha /^{\circ}$ & 90 \\
\hline$\beta /{ }^{\circ}$ & $109.943(11)$ \\
\hline$\gamma /{ }^{\circ}$ & 90 \\
\hline Volume $/ \AA^{3}$ & $659.56(11)$ \\
\hline$Z$ & 4 \\
\hline$\rho_{\text {calc }} / \mathrm{g} \mathrm{cm}^{-3}$ & 1.215 \\
\hline$\mu / \mathrm{mm}^{-1}$ & 0.764 \\
\hline$F(000)$ & 264.0 \\
\hline Radiation & $\mathrm{Cu}_{\mathrm{K} \alpha}(\lambda=1.54184)$ \\
\hline $2 \theta$ range for data collection $/{ }^{\circ}$ & $6.8-139.962$ \\
\hline Index ranges & $\begin{array}{l}-11 \leq h \leq 11,-6 \leq k \leq 6 \\
-16 \leq l \leq 16\end{array}$ \\
\hline Reflections collected & 5431 \\
\hline Independent reflections & $2475\left[R_{\text {int }}=0.0515, R_{\text {sigma }}=0.0500\right]$ \\
\hline Data/restraints/parameters & $2475 / 1 / 189$ \\
\hline Goodness-of-fit on $F^{2}$ & 1.025 \\
\hline Final $R$ indices $[I \geq 2 \sigma(I)]$ & $R_{1}=0.0687, \mathrm{w} R_{2}=0.1864$ \\
\hline Final $R$ indices [all data] & $R_{1}=0.0829, \mathrm{w} R_{2}=0.2039$ \\
\hline $\begin{array}{l}\text { Largest diff. } \\
\text { peak/hole / e } \AA^{-3}\end{array}$ & $0.35 /-0.26$ \\
\hline Flack parameter & $0.0(2)$ \\
\hline
\end{tabular}

the heterocompound has a general formula of $\mathrm{V}_{3} \mathrm{~L}$. Since one of the independent positions has a mixed occupation in the crystal structure, two kinds of dimers exist: homomolecular Val-Val and heteromolecular Val-Leu ones. The dimers are connected to each other via hydrogen bonds in the $b c$ plane and, therefore, form a layer with a thickness of one dimer molecule. The layers, in turn, are interlinked via van der Waals bonds (Fig. 9a).

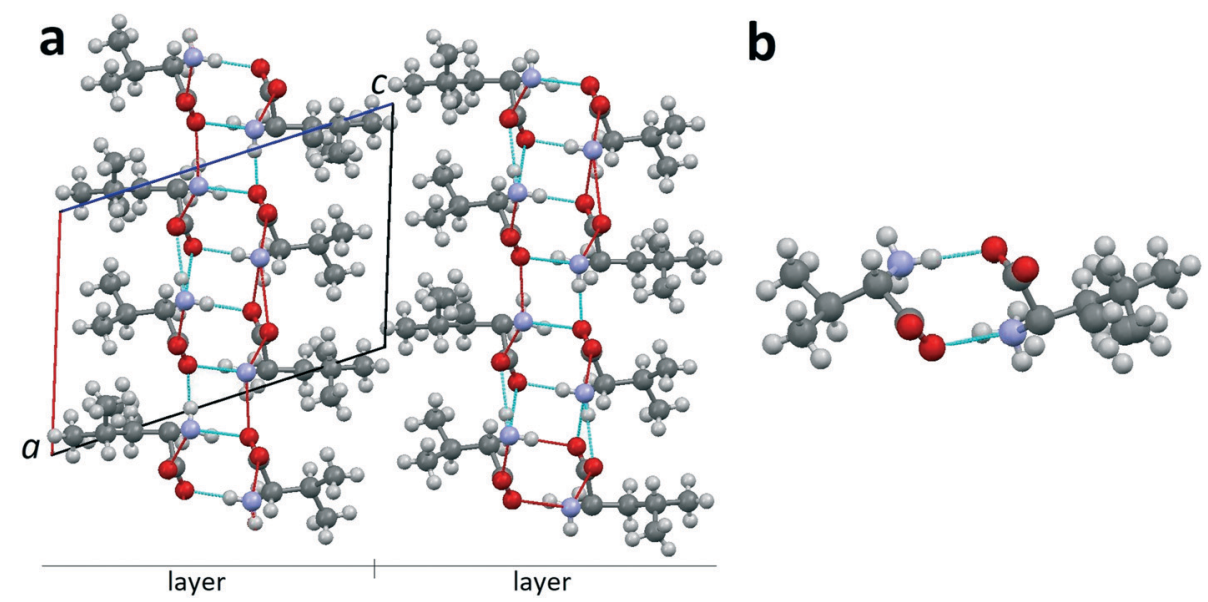

Fig. 9 (a) Projection of the crystal structure of non-equimolar discrete heterocompound $V_{3} L$ on the ac plane of the monoclinic cell. ${ }^{42}$ (b) Dimer molecule of heterocompound $\mathrm{V}_{3} \mathrm{~L}$; occupation degree of the left position is $100 \%$ Val; occupancy of the right position is mixed: $50 \%$ Val and $50 \%$ Leu. Images are constructed in the program Mercury ${ }^{40}$ using the structural data CCDC 1903257. 


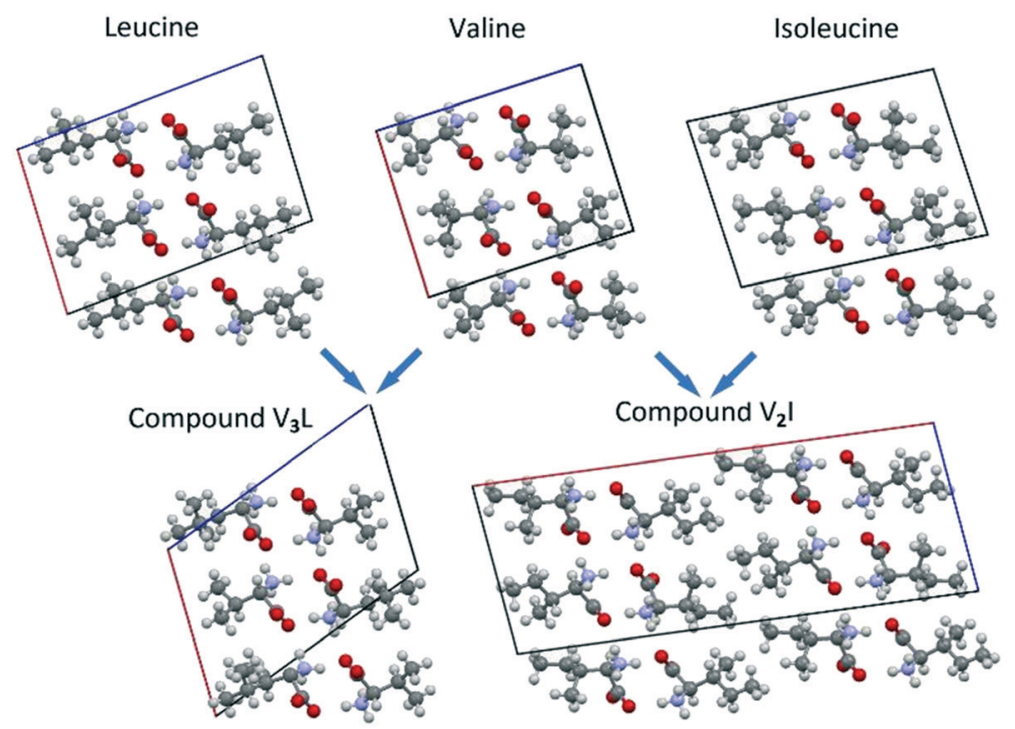

Fig. 10 Projections of Leu, Val, Ile, $V_{3} L$ and $V_{2} l$ crystal structures on the corresponding planes of their monoclinic cells.

\subsection{Discussion}

In Fig. 10, the projections of the crystal structures of Leu, Val and Ile are opposed to those of the respective heterocompounds $\mathrm{V}_{3} \mathrm{~L}$ and $\mathrm{V}_{2} \mathrm{I}$. In addition, Table 6 contains the corresponding monoclinic cell parameters for the mentioned compounds.

As shown, the crystal structure of compound $\mathrm{V}_{3} \mathrm{~L}$ closely resembles the structures of Leu, Val, and Ile enantiomers (Fig. 10). In the four compounds, the monoclinic cell comprises four molecules, and its asymmetric unit includes two molecules. Linear parameters $a, b$, and $c$ and volume $V$ of the monoclinic cells have close values as well. The angular parameter $\beta$ of heterocompound $\mathrm{V}_{3} \mathrm{~L}$ is notably larger than those of the Leu, Val, and Ile enantiomers (Fig. 10 and Table 6).

The molecular components of both non-equimolar heterocompounds $\mathrm{V}_{3} \mathrm{~L}$ and $\mathrm{V}_{2} \mathrm{I}$ have the same (L) chirality and both have disordered molecular positions. Nevertheless, the comprehensive analysis of the crystal structures of $\mathrm{V}_{3} \mathrm{~L}$ and $\mathrm{V}_{2} \mathrm{I}$ revealed substantial differences. First, in the case of compound $\mathrm{V}_{3} \mathrm{~L}$, only a half of the molecular positions show mixed occupation (Fig. 11a), while in compound $\mathrm{V}_{2} \mathrm{I}$, all the molecular positions exhibit mixed occupation (Fig. 11b). Second, the monoclinic cell of $\mathrm{V}_{3} \mathrm{~L}$ comprises four molecules, while that of $\mathrm{V}_{2} \mathrm{I}$ includes eight molecules, i.e. it is doubled in the direction of the longest axis of the cell. ${ }^{27}$
The molecular components' conformations of nonequimolar heterocompounds $\mathrm{V}_{3} \mathrm{~L}$ and $\mathrm{V}_{2} \mathrm{I}$ are discussed below. For convenience, the extended conformation of molecules is marked with superscript e ( $\mathrm{Val}^{\mathbf{e}}$ and $\left.\mathrm{Ile}^{\mathbf{e}}\right)$ and the folded conformation with symbol $\mathbf{f}\left(\mathrm{Val}^{\mathbf{f}}\right.$ and $\left.\mathrm{Ile}^{\mathbf{f}}\right)$. As it was already mentioned, there are no conformations attributed to Leu molecules.

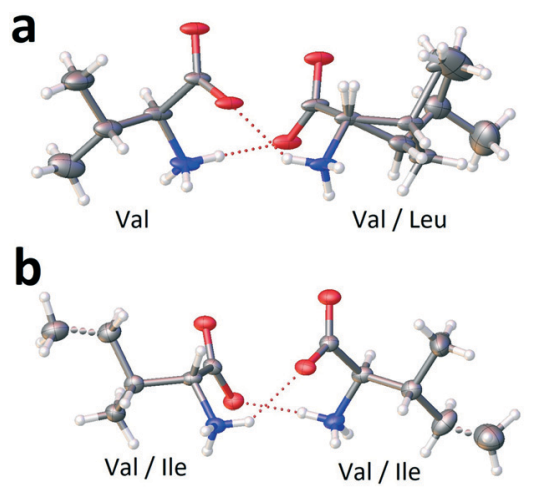

Fig. 11 Occupancy of molecular positions in the dimers of nonequimolar heterocompounds $V_{3} L$ (a) and $V_{2} I(b)$. Ellipsoids reflect the $20 \%$ and $50 \%$ probabilities in the case of $V_{3} L$ and $V_{2} l$, correspondingly. Images are constructed in the service OLEX2. ${ }^{44}$

Table 6 Parameters of the monoclinic cells of the lle, Val, and Leu enantiomers and non-equimolar compounds $V_{3} L$ and $V_{2} l$ produced in the $L-V a l-L-$ Leu and L-Val-L-Ile systems, respectively

\begin{tabular}{lllllcl}
\hline Compound & S. G. & $a, \AA$ & $b, \AA$ & $c, \AA$ & $\beta$, deg. & $V, \AA^{3}$ \\
\hline L-Ile & $P 2_{1}$ & $9.75(2)$ & $5.32(2)$ & $14.12(2)$ & $95.8(2)$ & 723 \\
L-Val & $P 2_{1}$ & $9.71(1)$ & $5.27(2)$ & $12.06(2)$ & $90.8(2)$ & 617.07 \\
L-Leu & $P 2_{1}$ & $9.562(2)$ & $5.301(1)$ & $14.519(3)$ & $94.20(2)$ & 733.965 \\
V & $P 2_{1}$ L & $9.6267(7)$ & $5.2704(2)$ & $13.829(2)$ & $109.94(1)$ & 659.6 \\
V $_{2} \mathrm{I}$ & $C 2$ & $25.7697(14)$ & $5.2445(2)$ & $9.6681(6)$ & $97.215(5)$ & 1296.29
\end{tabular}


Table 7 Population of the molecular positions in discrete heterocompounds $V_{3} L$ and $V_{2} I$ and the types of dimers comprising the molecules of $V a l$ and lle considering both the extended $\mathrm{e}$ and folded $\mathrm{f}$ conformations

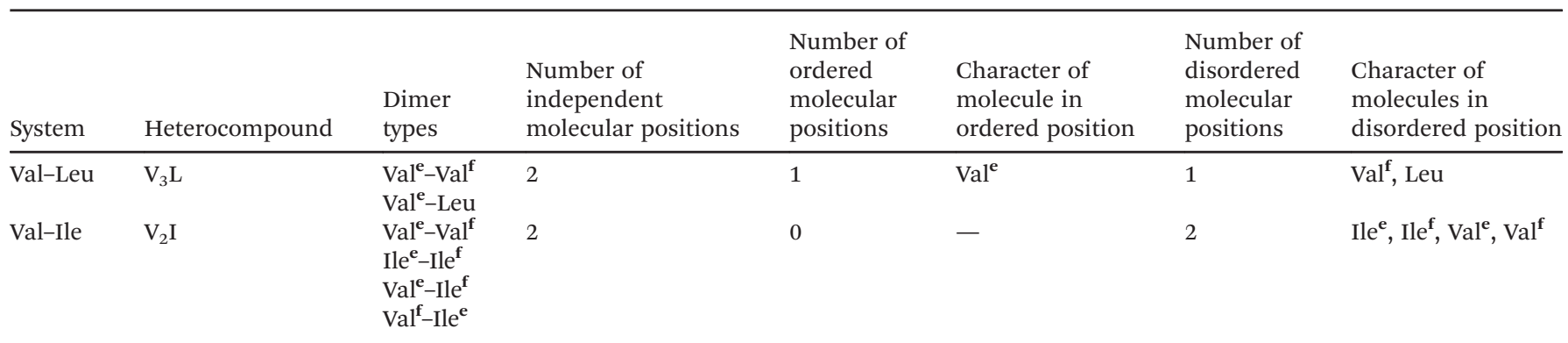

As given above, heterocompound $\mathbf{V}_{3} \mathbf{L}$ is characterized by one ordered and one disordered positions in the asymmetric unit. A 50/50 statistically mixed population of the disordered position implies that in every monoclinic cell, one dimer is composed solely of Val molecules (homomolecular dimer) and the other dimer is composed of both Val and Leu molecules (heteromolecular dimer) (Fig. 11a). One of the valine molecules in the homomolecular dimer has extended conformation $\mathrm{Val}^{\mathrm{e}}$, while the other molecule has folded conformation $\mathrm{Val}^{\mathrm{f}}$ (dimer $\mathrm{Val}^{\mathrm{e}}-\mathrm{Val}^{\mathrm{f}}$ ). The valine molecule in the heteromolecular dimer shows extended conformation $\mathrm{Val}^{\mathrm{e}}$ (dimer $\mathrm{Val}^{\mathrm{e}}$-Leu). It means that the ordered position is occupied by valine molecules having the extended conformation only, while the disordered position is populated with valine molecules having the folded conformation and leucine molecules (Table 7).

The monoclinic cell of heterocompound $\mathbf{V}_{2} \mathbf{I}$ has two independent molecular positions and both are disordered, i.e. characterized by mixed occupation. Molecules occupying one of these independent positions have extended conformation, while molecules present in the other independent position have folded conformation. Consequently, the crystal structure contains dimers of four types, namely, homomolecular dimers $\mathrm{Val}^{\mathbf{e}}-\mathrm{Val}^{\mathbf{f}}$ and $\mathrm{Ile}^{\mathbf{e}}-\mathrm{Ile}^{\mathbf{f}}$ and heteromolecular dimers $\mathrm{Val}^{\mathbf{e}}-\mathrm{Ile}^{\mathbf{f}}$ and $\mathrm{Val}^{\mathbf{f}}-\mathrm{Ile}^{\mathbf{e}}$ (Table 7).

Therefore, it can be concluded that the currently known non-equimolar heterocompounds of amino acids can be divided into two groups. $\mathrm{V}_{3} \mathrm{~L}$ as the compound of the first group contains two independent molecular positions and only one of them is disordered, while $\mathrm{V}_{2} \mathrm{I}$ as the compound belonging to the second group has all its molecular positions disordered. It should be noted that in the L-isoleucine- $\mathrm{L}^{-}$ leucine system, the recently found compound $\mathrm{I}_{3} \mathrm{~L}$ belongs, apparently, to the first group. The results of its investigation were presented at a conference ${ }^{45}$ and will be published later.

\section{Summary}

Peculiarities of the crystal chemistry of heterocompounds formed by $\alpha$-amino acids, i.e. compounds consisting of enantiomers of two different $\alpha$-amino acids, have been reviewed and studied. The consideration is complicated by the lack of a common approach for terminology and allocation of compounds with chiral molecules in the literature. This complication for multi-component crystals, in general, was mentioned also, for example, by G. R. Desiraju et $a{ }^{46}{ }^{46}$ To improve this situation, a classification of discrete compounds formed in binary chiral systems either by a single substance (homomolecular compounds) or by different substances (heteromolecular compounds) is proposed. The classification is based on both chemical and crystallographic characteristics of the discrete compounds. The concept of homo- and heteromolecular dimers is introduced based on the analysis of published results for amino acid equimolar heterocompounds. Heterocompounds composed of homomolecular dimers are characterized by alternating the dimer molecules of each substance, while those consisting of heteromolecular dimers are characterized by the dimer molecules of different substances. The correlation found between the dimer type and the side chain structure (linear or branched) and the conformation (extended or folded) of the relevant heterocompounds' molecules is discussed.

Equimolar heterocompounds of amino acids having different chiralities are known from the published literature. Their crystallochemical characteristics were analyzed based on the data available from the CSD and other sources. The proposed concept of homo- and heteromolecular dimers allowed the division of the known equimolar heterocompounds into two groups: those with homo- and those with heteromolecular dimers. It was found that the molecules of the same substance have different conformations in the homo- and heteromolecular dimers. In the case of the equimolar homocompounds (true racemates), the branched side chain molecules have a folded conformation, while in the case of the equimolar heterocompounds, they are characterized by an extended conformation. Equimolar heterocompounds of amino acids having the same chirality have not yet been found in the published literature.

Non-equimolar heterocompounds are very rare. Only three examples of the compounds of chiral substances have been reported in the literature. Two compounds consist of molecules having different chiralities and their crystal structures are unknown. ${ }^{14}$ The third compound was described by the present authors ${ }^{27}$ and is an example of a non-equimolar heterocompound composed of the same 
chirality molecules. The crystal structure of this compound $\mathrm{V}_{2} \mathrm{I}$, formed in the system L-Val-L-Ile, is characterized by two disordered molecular positions in the asymmetric unit of its monoclinic cell (S. G. C2). A recently revealed further example is compound $\mathrm{V}_{3} \mathrm{~L}$ in the system $\mathrm{L}$-Val-L-Leu. Its crystal structure exhibits one ordered and one disordered molecular positions in the asymmetric unit of its monoclinic cell (S. G. $P 2_{1}$ ), thus differing from the crystal structure of heterocompound $\mathrm{V}_{2} \mathrm{I}$. The crystal structures of $\mathrm{V}_{2} \mathrm{I}$ and $\mathrm{V}_{3} \mathrm{~L}$ were analyzed using the concepts of homo- and heteromolecular dimers, side chain types (linear or branched) and molecular conformations (extended or folded). Of course, further assessment of the presented structural trends requires more data. Thus, in view of the poor quantity of known crystal structures of non-equimolar compounds, there is an obvious need for continuation of their investigations.

\section{Conflicts of interest}

There are no conflicts of interest to declare.

\section{Acknowledgements}

The investigations were performed using equipment of the Resource Centre "Centre for X-ray Diffraction Studies" of St. Petersburg State University. The authors appreciate the financial support provided by the Russian Foundation for Basic Research (Project 18-35-00183 mol_a). Open Access funding provided by the Max Planck Society.

\section{Notes and references}

1 A. D. McNaught and A. Wilkinson, Compendium of Chemical Terminology, Blackwell Scientific Publications, Oxford, 2nd edn, 1997, p. 464.

2 A. I. Kitaigorodsky, Molecular crystals, Nauka, Moscow, 1971, p. 424(Rus).

3 G. R. Desiraju, Crystal Engineering: From Molecule to Crystal, J. Am. Chem. Soc., 2013, 135(27), 9952-9967.

4 A. M. Rouhi, Chiral Chemistry, Chem. Eng. News, 2004, 82(24), 47-62.

5 H. Murakami, From Racemates to Single Enantiomers Chiral Synthetic Drugs over the last 20 Years, Top. Curr. Chem., 2007, 269, 273-299.

6 J. Jacques, A. Collet and S. H. Wilen, Enantiomers, Racemates and Resolutions, J. Wiley \& Sons, New York, 1981, p. 233.

7 C. H. Görbitz, Crystal structures of amino acids: from bond lengths in glycine to metal complexes and high pressure polymorphs, Crystallogr. Rev., 2015, 21(3), 160-212.

8 E. V. Boldyreva, Combined X-ray diffraction and Raman spectroscopy studies of phase transitions in crystalline amino acids at low temperatures and high pressures: selected examples, Phase Transitions, 2009, 82(4), 303-321.

9 E. N. Kotelnikova, A. I. Isakov and H. Lorenz, Non-equimolar discrete compounds in binary chiral systems of organic substances, CrystEngComm, 2017, 19, 1851-1869.
10 G. A. Morales and F. R. Fronczek, A Kryptoracemic Hydroperoxide, Acta Crystallogr., Sect. C: Cryst. Struct. Commun., 1996, 52(5), 1266-1268.

11 R. Bishop and M. L. Scudder, Multiple Molecules in the Asymmetric Unit $\left(\mathrm{Z}^{\prime}>1\right)$ and the Formation of False Conglomerate Crystal Structures, Cryst. Growth Des., 2009, 9(6), 2890-2894.

12 M. Bergmann and M. Lissitzin, Die überzähligen Stereoisomeren der $\gamma$-Amino- $\beta$-oxy-buttersäure, Ber. Dtsch. Chem. Ges., 1930, 63(2), 310-313.

13 A. A. Bredikhin, Z. A. Bredikhina, D. V. Zakharychev, A. I. Samigullina and A. T. Gubaidullin, 4-Benzoylamino-3hydroxybutyric Acid, Historically First "Anomalous Racemate": Reinvestigation, Cryst. Growth Des., 2015, 15(3), 1362-1373.

14 A. Fredga, Steric correlations by the quasi-racemate method, Tetrahedron, 1960, 8, 126-144.

15 M. D. Eddleston, M. Arhangelskis, T. Fričšić and W. Jones, Solid state grinding as a tool to aid enantiomeric resolution by cocrystallization, Chem. Commun., 2012, 48, 11340-11342.

16 B. Dalhus and C. H. Görbitz, Molecular aggregation in selected crystalline 1:1 complexes of hydrophobic D- and L-amino acids. II. The D-norleucine series, Acta Crystallogr., Sect. C: Cryst. Struct. Commun., 1999, 55(7), 1105-1112.

17 M. Andersson, A. Fredga and B. Jerslev, Anomalous Racemates of Malic Acid, Acta Chem. Scand., 1966, 20, 1060-1063.

18 B. Dalhus and C. H. Görbitz, Non-centrosymmetric racemates: space-group frequencies and conformational similarities between crystallographically independent molecules, Acta Crystallogr., Sect. B: Struct. Sci., 2000, 56(4), 715-719.

19 A. I. Isakov, E. N. Kotelnikova and H. Lorenz, NonEquimolar Discrete Phases Formed in the System of Malic Acid Enantiomers, Chem. Eng. Technol., 2015, 38(6), 1047-1052.

20 M. E. Breen, S. L. Tameze, W. G. Dougherty, W. S. Kassel and K. A. Wheeler, Structural Studies of Enantiomers, Racemates, and Quasiracemates. 2-(3-Bromophenoxy) propionic Acid and 2-(3-Methoxyphenoxy)propionic Acid, Cryst. Growth Des., 2008, 8(10), 3863-3870.

21 M. S. Hendi, R. E. Davis, V. M. Lynch and K. A. Wheeler, Structural studies of enantiomers, racemates, and quasiracemates. 2-(2,4-dichlorophenyl)propanoic acid and 2-(2-chloro-4-nitrophenyl)propanoic acid, Cryst. Eng., 2001, 4, 11-24.

22 M. S. Hendi, P. Hooter, R. E. Davis, V. M. Lynch and K. A. Wheeler, Structural Studies of Enantiomers, Racemates, and Quasiracemates: N-(4-Methylbenzoyl)methylbenzylamine and N-(4-Nitrobenzoyl)methylbenzylamine, Cryst. Growth Des., 2004, 4(1), 95-101.

23 S. L. Fomulu, M. S. Hendi, R. E. Davis and K. A. Wheeler, Structural Studies of Enantiomers, Racemates, and Quasiracemates. 2-(2,4,5-Trichloroanilino)propanoic Acid and 2-(2,4,5-Trichlorophenoxy)propanoic Acid, Cryst. Growth Des., 2002, 2(6), 637-644. 
24 S. L. Fomulu, M. S. Hendi, R. E. Davis and K. A. Wheeler, Structural Studies of Enantiomers, Racemates, and Quasiracemates. N-(2-Chlorobenzoyl)methylbenzylamine and N-(2-Bromobenzoyl)methylbenzylamine, Cryst. Growth Des., 2002, 2(6), 645-651.

25 J. T. Cross, N. A. Rossi, M. Serafin and K. A. Wheeler, Tröger's base quasiracemates and crystal packing tendencies, CrystEngComm, 2014, 16, 7251-7258.

26 C. B. Aakeröy, T. I. Cooke and M. Nieuwenhuyzen, The crystal structure of the molecular cocrystal L-malic acid L-tartaric acid (1/1), Supramol. Chem., 1996, 7(2), 153-156.

27 A. I. Isakov, E. N. Kotelnikova, S. Muenzberg, S. N. Bocharov and H. Lorenz, Solid Phases in the System L-Valine - LIsoleucine, Cryst. Growth Des., 2016, 16, 2653-2661.

28 C. H. Görbitz and P. Karen, Twin Displacive Transitions in Amino Acid Quasiracemates, J. Phys. Chem. B, 2015, 119(15), 4975-4984.

29 B. Dalhus and C. H. Görbitz, Molecular aggregation in crystalline 1:1 complexes of hydrophobic D- and L-amino acids. I. The L-isoleucine series, Acta Crystallogr., Sect. B: Struct. Sci., 1999, 55(3), 424-431.

30 B. Dalhus and C. H. Görbitz, Structural relationships in crystals accommodating different stereoisomers of 2-amino3-methylpentanoic acid, Acta Crystallogr., Sect. B: Struct. Sci., 2000, 56(4), 720-727.

31 B. Dalhus and C. H. Görbitz, Molecular aggregation in selected crystalline 1:1 complexes of hydrophobic D- and L-amino acids. III. The L-leucine and L-valine series, Acta Crystallogr., Sect. C: Cryst. Struct. Commun., 1999, 55(9), 1547-1555.

32 C. H. Görbitz, K. Rissanen, A. Valkonen and Å. Husabø, Molecular aggregation in selected crystalline 1:1 complexes of hydrophobic D- and L-amino acids. IV. The L-phenylalanine series, Acta Crystallogr., Sect. C: Cryst. Struct. Commun., 2009, 65(6), o267-0272.

33 B. Dalhus and C. H. Görbitz, Crystal Structures of Hydrophobic Amino Acids. I. Redeterminations of L-Methionine and L-valine at $120 \mathrm{~K}$, Acta Chem. Scand., 1996, 50, 544-548.

34 B. Dalhus and C. H. Görbitz, Triclinic Form of DL-Valine, Acta Crystallogr., Sect. C: Cryst. Struct. Commun., 1996, 52(7), 1759-1761.

35 C. H. Görbitz and B. Dalhus, Redetermination of L-Leucine at $120 \mathrm{~K}$, Acta Crystallogr., Sect. C: Cryst. Struct. Commun., 1996, 52(7), 1754-1756.

36 E. N. Kotelnikova, A. I. Isakov, L. Yu. Kryuchkova and H. Lorenz, Acids with Chiral Molecules as Essential Organic
Compounds of Biogenic-Abiogenic Systems, in Processes and Phenomena on the Boundary between Biogenic and Abiogenic Nature, ed. O. V. Frank-Kamenetskaya, D. Y. Vlasov, E. G. Panova and S. N. Lessovaia, Springer, 2019, Lecture Notes in Earth System Sciences.

37 A. I. Isakov, E. N. Kotelnikova, S. N. Bocharov, A. A. Zolotarev Jr and H. Lorenz, Thermal deformations of the crystal structures of L-valine, L-isoleucine and discrete compound $\mathrm{V}_{2} \mathrm{I}$, in BIWIC 2013 - 23rd International Workshop on Industrial Crystallization, ed. H. Lorenz and H. Buchholz, Cuvillier Verlag, Göttingen, 2016, pp. 7-12.

38 A. I. Isakov, E. N. Kotelnikova, S. N. Bocharov, A. A. Zolotarev Jr and H. Lorenz, Thermal deformations of the crystal structures of L-valine, L-isoleucine and discrete compound $\mathrm{V}_{2} \mathrm{I}$, in BIWIC 2013 - 23rd International Workshop on Industrial Crystallization, ed. H. Lorenz and H. Buchholz, Cuvillier Verlag, Göttingen, 2016, pp. 7-12.

39 C. H. Görbitz, P. Karen, M. Dušek and V. Petříček, An exceptional series of phase transitions in hydrophobic amino acids with linear side chains, IUCrJ, 2016, 3(5), 341-353.

40 C. F. Macrae, I. J. Bruno, J. A. Chisholm, P. R. Edgington, P. McCabe, E. Pidcock, L. Rodriguez-Monge, R. Taylor, J. van de Streek and P. A. Wood, Mercury CSD 2.0 - new features for the visualization and investigation of crystal structures, J. Appl. Crystallogr., 2008, 41(2), 466-470.

41 C. H. Görbitz, B. Dalhus and G. M. Day, Pseudoracemic amino acid complexes: blind predictions for flexible twocomponent crystals, Phys. Chem. Chem. Phys., 2010, 12, 8466-8477.

42 CCDC 1903257.

43 C. H. Görbitz and B. Dalhus, L-isoleucine, Redetermination at $120 \mathrm{~K}$, Acta Crystallogr., Sect. C: Cryst. Struct. Commun., 1996, 52(6), 1464-1466.

44 O. V. Dolomanov, L. J. Bourhis, R. J. Gildea, J. A. K. Howard and H. Puschmann, OLEX2: a complete structure solution and analysis program, J. Appl. Crystallogr., 2009, 42(2), 339-341.

45 L. Yu. Kryuchkova, E. N. Kotelnikova, A. A. Zolotarev Jr and H. Lorenz, Limits of solid solutions in the L-leucine-Lisoleucine system according to PXRD and SCXRD data, in BIWIC 2018 - 25th International Workshop on Industrial Crystallization, ed. Y. Cartigny and N. Couvrat, Rouen, 2018, p. 225.

46 G. R. Desiraju, J. J. Vittal and A. Ramanan, Crystal Engineering: A Textbook, World Scientific Publishing Co. Pte. Ltd., Singapore, 2011, p. 131. 